\title{
Erratum to: Is there any benefit using low-intensity inspiratory and peripheral muscle training in heart failure? A randomized clinical trial
}

\author{
Tatiana Satie Kawauchi ${ }^{1}$ - Iracema Ioco Kikuchi Umeda ${ }^{2}$ Lays Magalhães Braga ${ }^{1}$. \\ Antonio de Pádua Mansur ${ }^{3}$ - João Manoel Rossi-Neto ${ }^{2}$ - Amanda Guerra de Moraes Rego Sousa ${ }^{2}$. \\ Mário Hiroyuki Hirata ${ }^{2} \cdot$ Lawrence P. Cahalin $^{4} \cdot$ Naomi Kondo Nakagawa $^{1}$
}

Published online: 10 July 2017

(C) Springer-Verlag GmbH Germany 2017

\section{Erratum to: Clin Res Cardiol DOI 10.1007/s00392-017-1089-y}

Unfortunately, an incorrect figure was provided in the original manuscript. Figure 1 has to be substituted by Fig. 2. A new Fig. 2 is now provided. The correct Figs. 1 and 2 with according captions are given below.

After the NYHA functional class analysis using the McNemar test, the $p$ value is missing in the Results section

The online version of the original article can be found under doi:10.1007/s00392-017-1089-y.

Naomi Kondo Nakagawa

naomikondo@uol.com.br

Tatiana Satie Kawauchi

tatikawauchi@gmail.com

Iracema Ioco Kikuchi Umeda

iikumeda@usp.br

Lays Magalhães Braga

laysmbraga@yahoo.com.br

Antonio de Pádua Mansur

apmansur@yahoo.com

João Manoel Rossi-Neto

jmrossi@sti.com.br

Amanda Guerra de Moraes Rego Sousa amandars@uol.com of the Abstract. The correct text is reproduced below.

Results All groups showed similar quality-of-life improvements. Low and moderate intensities training programs improved inspiratory muscle strength, peripheral muscle strength, and walking distance. However, only moderate intensity improved expiratory muscle strength and NYHA functional class $(p=0.031)$ in HF patients.

Mário Hiroyuki Hirata

mhhirata@usp.br

Lawrence P. Cahalin

1.cahalin@miami.edu

1 Department of Physiotherapy, LIM-34, Faculdade de Medicina da Universidade de São Paulo, Av. Dr. Arnaldo, 455 Room 1150, São Paulo, SP 01246-930, Brazil

2 Dante Pazzanese Institute of Cardiology São Paulo State, Av. Dr. Dante Pazzanese, 500, São Paulo, SP, Brazil

3 Heart Institute - HCFMUSP, Faculdade de Medicina da Universidade de Sao Paulo, Av. Dr. Eneas de Carvalho Aguiar, 44, São Paulo, SP, Brazil

4 Department of Physical Therapy, University of Miami, Coral Gables, FL, USA 


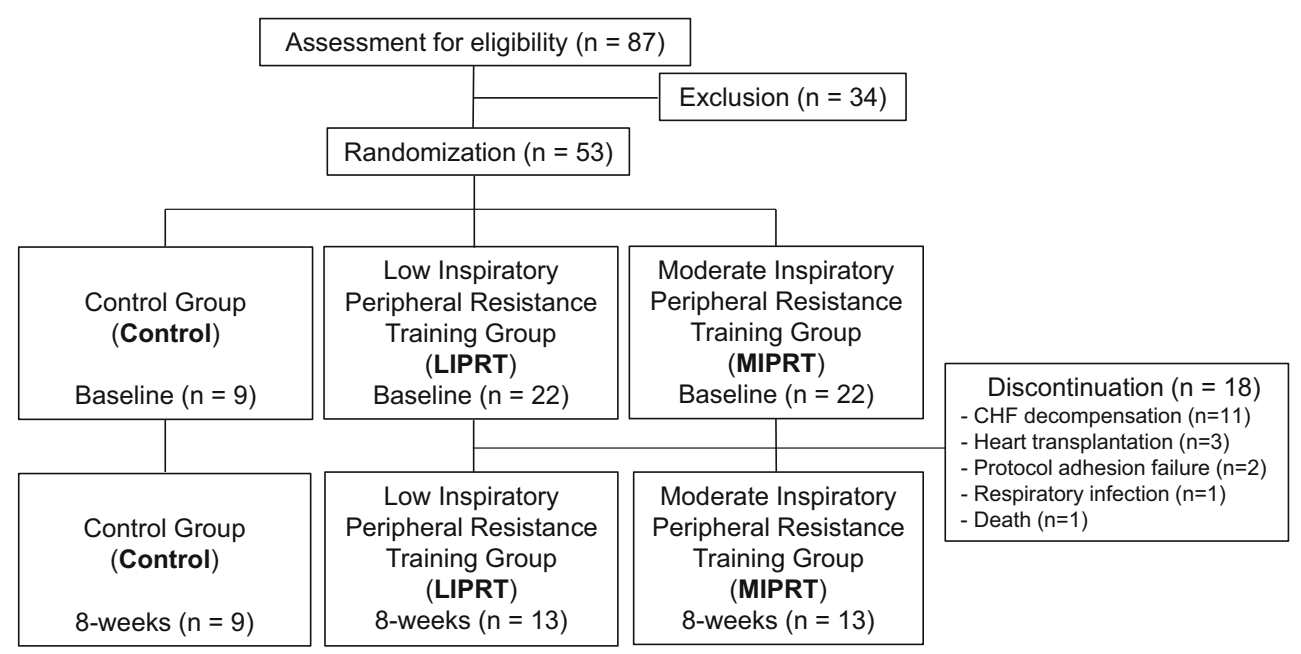

Fig. 1 CONSORT diagram showing subject recruitment and study inclusion/exclusion

Panel A
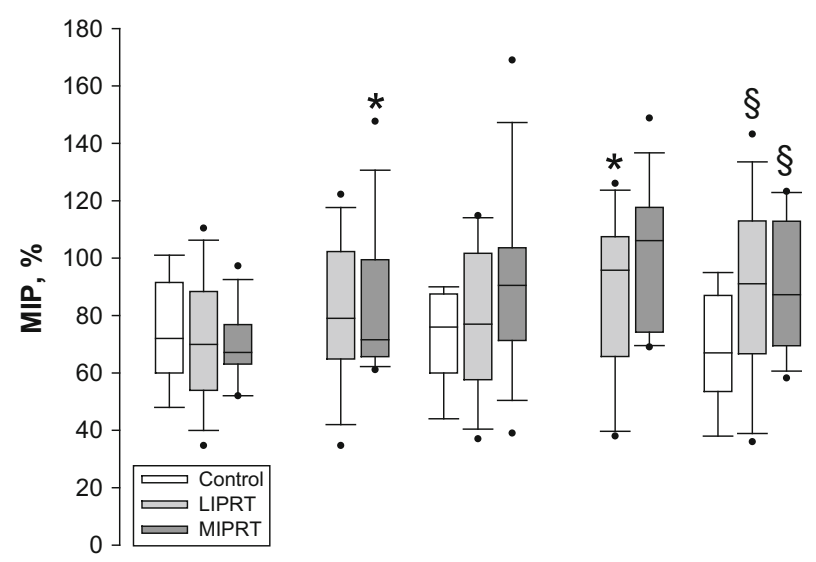

Panel B
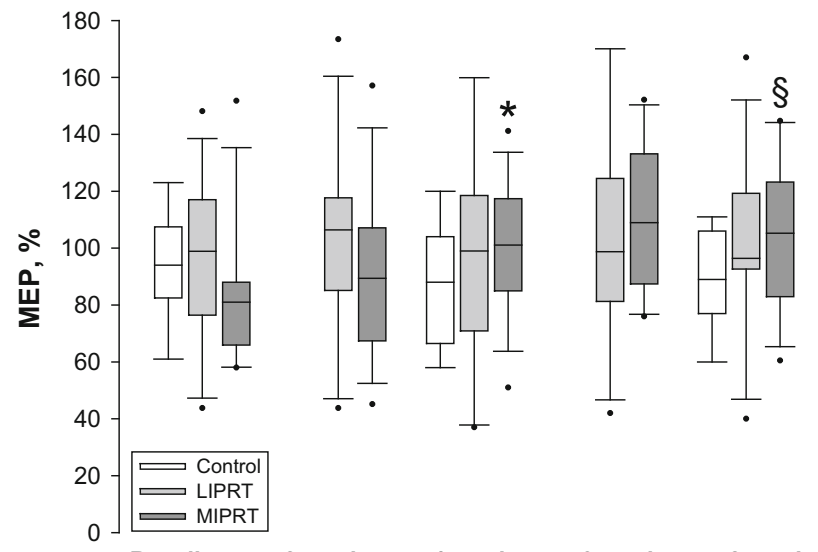

Baseline

2-weeks

4-weeks

6-weeks

8-weeks

Fig. 2 Respiratory muscle strength at baseline, 2, 4, 6, and 8 weeks in the control, low inspiratory and peripheral resistance training (LIPRT), and moderate inspiratory and peripheral resistance training (MIPRT) groups, as assessed using linear mixed models and post hoc analysis with Tukey test. ${ }^{*} p<0.05$ vs. baseline, ${ }^{\S} p<0.05$ vs. control at the same time point 